\title{
Evidence that the house finch (Carpodacus mexicanus) uses scent to avoid omnivore mammals
}

\author{
Luisa Amo ${ }^{1,2^{*}}$, Isabel López-Rull1', Iluminada Pagán ${ }^{1}$ and Constantino Macías García
}

\begin{abstract}
Background: The detection of predator chemical cues is an important antipredatory behaviour as it allows an early assessment of predation risk without encountering the predator and therefore increases survival. For instance, since chemical cues are often by-products of metabolism, olfaction may gather information not only on the identity but also about the diet of predators in the vicinity. Knowledge of the role of olfaction in the interactions of birds with their environment, in contexts as important as predator avoidance, is still scarce. We conducted two two-choice experiments to explore 1) whether the house finch Carpodacus mexicanus can detect the chemical cues of a marsupial predatory mammal, the common opossum (Didelphis marsupialis), and 2) whether its response to such cues is influenced by the recent diet of this omnivorous predator, as this would increase the accuracy with which the risk of predation is assessed.
\end{abstract}

Results: House finches avoided the area of the apparatus containing the scent of the predator, and this effect did not depend on the recent diet (bait used to lace the traps) of the predator.

Conclusions: Our results provide clear evidence that house finches detect and use the chemical cues of predators to assess the level of predation risk of an area and avoid it.

Keywords: Carpodacus mexicanus; Olfaction; Omnivorous predator; Predation risk; Predator diet; Predator chemical cues

\section{Background}

The avoidance of predation is a ubiquitous challenge for most animals, which has prompted the evolution of defence mechanisms, such as the ability to ascertain the presence of predators (Lima and Dill 1990). One means of detecting predators without increasing the risk of being perceived by them is to recognise their scent (Kats and Dill 1998). However, the use of chemical cues from predators can also lead to an overestimation of risk if the animal continues to avoid the area containing those cues when the predator is no longer present or is not willing to perform an attack (Kats and Dill 1998; Smith and Belk 2001). Therefore, according to the threat sensitive hypothesis (Helfman 1989), natural selection should

\footnotetext{
* Correspondence: luisa.amo@mncn.csic.es

'Departamento de Ecología Evolutiva, Instituto de Ecología, Universidad Nacional Autónoma de México, Apartado Postal 70-275, México DF 4510, México

${ }^{2}$ Present address: Departamento de Ecología Evolutiva, Museo Nacional de Ciencias Naturales, C/ José Gutiérrez Abascal, 2., Madrid 28006, Spain
}

favour individuals that display antipredatory responses with an intensity that matches the current risk of predation rather than respond to all predator chemical cues in a similar way. Chemical cues from predators may not only signal the presence of a predator but also provide useful information for the prey such as the diet of the predator. This may be especially important for prey of omnivorous predators, which may temporarily specialise in feeding on different food sources as a consequence of availability or be individually specialised in hunting particular types of prey or eating certain types of food regardless of their availability (Cantor et al. 2013). For example, individual variation in resource use by opossums (Didelphis albiventris) leads to differences in the type of fruit consumed and causes asymmetries in seed dispersal efficiency within the population (Cantor et al. 2013). The ability to discriminate predator diet using olfaction may allow the prey to evaluate the level of risk posed by the predator, thus performing an adequate but 
not a costly and unnecessary antipredatory response, as revealed by studies showing that some prey species can distinguish between chemical cues from predators fed with different diets (e.g. Kiesecker et al. 2002; Vilhunen and Hirvonen 2003).

Although the use of chemical cues in predator recognition has been documented in a number of taxa (review in Kats and Dill 1998), the evidence in birds is both scant and conflicting. The first study that showed a clear antipredatory response to predator scent was performed with blue tits Cyanistes caeruleus in a reproductive context. Birds delayed their entry to the nest-box for longer when it contained predator scent than when a control scent was placed inside the nest-box. In addition, birds decreased the time spent inside the predator-scented nest-box when feeding nestlings (Amo et al. 2008). Roth et al. (2008) showed an avoidance response in house finches Carpodacus mexicanus exposed to predator and non-predatory mammal scent in a foraging context. The ability to detect predator scent seems to be innate in great tits Parus major (Amo et al. 2011a). Also, adult fowl Gallus gallus naïve to predator scent spent less time foraging and were more vigilant when exposed to predator than when exposed to non-predator faecal odour (Zidar and Løvlie 2012). Recently, it has been shown that fewer ducks nested in places marked with red fox (Vulpes vulpes) urine than in control places (Eichholz et al. 2012). However, other studies have not found a measurable response of birds to predator scent (Godard et al. 2007; Johnson et al. 2011). Therefore, it is clearly necessary to increase the knowledge about the ability of bird species to recognise chemical cues of predators and their capability to obtain information about the predator diet in order to accurately assess the risk of predation.

Olfaction was the largely neglected sense of birds. However, recent evidence suggest that, besides assessing predator chemical cues, birds use olfaction in several other contexts, from foraging (e.g. Nevitt 2011, Amo et al. 2013a, b) to social interactions including discrimination of species (Zhang et al. 2013, Krause et al. 2014), sex (Whittaker et al. 2011, Amo et al. 2012a) and even the relative quality/condition of individuals (Amo et al. 2012b). The importance of olfaction has been demonstrated amongst others in different species of Procelariiformes (e.g. Nevitt 2011, Bonadonnna and Nevitt Bonadonna and Nevitt 2004), Galliformes (Hirao et al. 2009), Spheniformes (Amo et al. 2013a) and Passeriformes (Whittaker et al. 2011, Amo et al. 2013b).

Here we explored the role of chemical cues of predators on the antipredatory behaviour of the house finch, C. mexicanus. In a previous study, Roth et al. (2008) could not disentangle whether house finches avoided the scent of a predator (house cat; Felis catus) because they were evading food contaminated with faeces or because they were reluctant to enter a risky area, given that the birds in their experiment also avoided the faeces of a nonpredatory mammal (the laboratory rabbit [Oryctolagus cunniculus]; Roth et al. 2008). Here we tested in a first experiment whether birds can detect the chemical cues of a marsupial predator. We offered birds the choice between a scented area and an unscented area. The scented area could have the scent of a predator or a novel scent (cologne). This design allows us to ascertain whether the avoidance response of birds is due to the aversion of a risky area containing predator chemical cues, and not to the avoidance of a novel scent (cologne). In a second experiment, we tested whether birds are able to discriminate the recent diet of an omnivorous predator to accurately assess the level of predation risk. Similar to previous studies (Amo et al. 2008), we hypothesised that birds may avoid the chemical cues of a predator. We also predicted that birds would react differently to scents of predators that have recently fed on birds than to those that have fed on fish.

\section{Methods}

\section{Study species}

The house finch is a small socially monogamous and sexually dichromatic passerine that breeds in both cavities and open nests (Thompson 1960). This species has been used as a model to study carotenoid-based plumage coloration, that is an honest signal of quality in males, and that it is selected for by females (Hill 1990, 1991). Previous evidence shows that this species is also able to use olfaction in a social context (Amo et al. $2012 \mathrm{~b}$ ), and also possibly in predator detection in a foraging context (Roth et al. 2008; see above).

We used 35 adult house finches (28 males and 7 females) captured at San Luis Potosí State, México, in February 2009 by professional bird catchers authorised by Secretaría del Medio Ambiente y Recursos Naturales (SEMARNAT), and taken to the Instituto de Ecología, Universidad Nacional Autónoma de México (UNAM; México City), where they were housed individually in cages $(33 \times 27 \mathrm{~cm}$ and $31 \mathrm{~cm}$ high) inside a roofed outdoor aviary at ambient temperature and under a natural photoperiod (see Amo et al. 2012b). Birds, which were ringed to allow individual identification, received a constant supply of commercial mixture of seeds for granivorous birds, and water ad libitum. The experiments were performed after 2 months of acclimatisation. Birds were healthy during the tests and did not exhibit signs of stress from the manipulation. As soon as birds returned to their cages, they resumed their habitual behaviour. After the experiment, the birds were placed in large aviaries for 2 weeks before being released at their capture location at the beginning of May (see Amo et al. 
2012b). Thus, in total, birds were kept in captivity for 3 months.

To obtain predator scent, we used the urine of the common opossum Didelphis marsupialis. Opposums are regular mesocarnivore predators of bird nests (Staller et al. 2005, Lumpkin et al. 2012, Melville et al. 2014) and they even prey on poultry (Amador-Alcala et al. 2013), although they also eat fruits, invertebrates and other small vertebrates (Eisenberg 1989). The common opossum is sympatric with house finches in the area where birds were captured (Eisenberg 1989). Since this is an omnivore predator, we were also able to evaluate the effect of recent predator diet on the responses of birds to its scent. Opossums were captured with Tomahawk traps baited either with chicken or with fish. Traps were set at the sunset (19:30) and checked at the sunrise (7:30) in the buffer areas of the Pedregal de San Angel Ecological Reserve that surround the Instituto de Ecología, UNAM. In this natural area, opossums can have a natural diet. Urine from the opossums impregnated the sheets of absorbent paper placed under the traps. We caught four different opossums, two in the chickenbaited and two in the fish-baited traps, and all had consumed the bait by sunrise, when we checked the traps and released them. The four opossums appeared healthy and did not look stressed upon release. From each opossum captured, we obtained two papers soiled with the scent. For the opossums fed with chicken bait, one paper was used in the first experiment, and the other paper was used in the second experiment. Absorbent papers soiled by the opossums were collected with gloves and frozen at $-20^{\circ} \mathrm{C}$ until being used in the experiments. During trials, each paper containing the predator scent was used for less than $2 \mathrm{~h}$.

\section{Experimental design}

The experiments were carried out in April 2009 using an olfactometry device described in Amo et al. 2012b (see Figure 1). The device and the methodology have been successfully used in assessing the olfactory ability of birds of several species (Amo et al. 2012a, b), including house finches (Amo et al. 2012b). Each bird was introduced in a small central plastic box that contained a fan that drew the air from the device (Figure 1). The device was only opened at the furthest walls of the choice chambers, where the scent stimuli where located, to allow airflow. The fan created a constant airflow through each of the scents and into the central chamber, so the focal bird received two separate draughts, each with the corresponding scent, for a 5-min period. Then the lateral doors of the central chamber were simultaneously opened giving the bird access to the two choice chambers. Each choice chamber was divided with screens into two sectors (Figure 1). In the further sectors of the choice chambers, there were situated the corresponding scents. Both the doors between the central and the choice chambers and the screens creating the sectors were made of a dense plastic mesh that allowed airflow but prevented the birds from seeing through them. The room in which the experiment was performed was in darkness - but very dim diffuse light allowed the observer to distinguish the silhouette of the experimental bird - and in complete silence, so the experimenter could perceive any noise coming from the device. The side of the chamber where the stimuli were presented was balanced amongst trials. Treatments were randomly assigned to birds.

We recorded as chosen the chamber into which the focal bird first entered after we remotely opened the doors. Movement could not be followed visually with any certainty in the experimental conditions, thus the bird's choice was determined by hearing the movement of the bird inside the chamber, and it was confirmed because as soon as the bird chose a chamber, the experimenter captured it inside this chamber. The validity of first choice as a measure of the interest of birds, including this species, in particular chemical stimuli has been previously demonstrated (e.g. Bonadonna and Nevitt 2004; Bonadonna et al. 2006; Amo et al. 2012a, b, Krause et al. 2014). To minimise the length of the trials, if the test bird did not leave the central chamber after $1 \mathrm{~min}$, we gently knocked on the middle of the entry door of the central chamber to prompt it to move to one of the

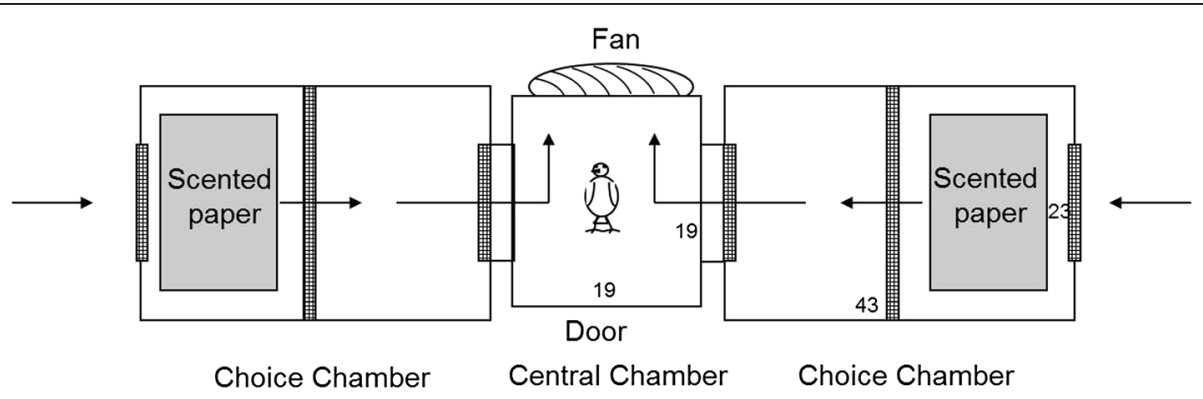

Figure 1 Representation of the olfactometry chamber. Arrows indicate airflow. 
choice chambers. Our records indicate that before knocking at the door, all birds were oriented towards the chamber they subsequently entered. The knocking on the door did not affect the preference of birds in previous studies with the same species and apparatus (Amo et al. 2012b), or in other tested species (Amo et al. 2012a). The device was carefully cleaned with commercial antibacterial, neutral $\mathrm{pH}$ soap, and allowed to air dry between trials.

Most birds were only used once in one of the two experiments, but five male birds were used in both experiments; in these cases, they were used only once in a day and were never tested on consecutive days. In order to prevent an avoidance response to the olfactometry device due to both choice chambers containing predator scent in experiment 2 , the five birds that were tested in the two experiments were tested first with the protocol of the experiment 1 and then with the protocol of experiment 2. As soon as the trial was over, birds were returned to their cages where they resumed their normal behaviour. The experiment was performed under licence of Secretaría del Medio Ambiente y Recursos Naturales.

\section{Experiment 1: detection of chemical cues of a marsupial nest predator}

We used 20 birds (13 males and 7 females) to test whether they detect and avoid the chemical cues of a non Carnivora predator. We compared the choice of birds when one of the chambers contained predator scent and the other chamber was odourless. In order to control for the presence of a novel scent, we included a treatment to compare the choice of birds when one of the chambers contained a novel scent and the other chamber had no odour added. In this treatment, we used commercial cologne as a source of a novel scent. The scents were provided by placing an absorbent paper with the correspondent scent (predator (opossum) or novel scent (cologne) in the experimental chamber. The control chamber contained a paper impregnated with water (odourless control). In half of the trials $(n=10)$, the experimental chamber contained the predator scent ( $n=2$ opossums); in the rest of the trials $(n=10)$, it contained a paper impregnated with a novel scent (cologne Revlon ${ }^{\mathrm{rm}}$, naté naturals red fruits, Revlon, New York City, USA). The order of treatments as well as the location of the scents was balanced between trials.

\section{Experiment 2: detection of the recent diet of an omnivorous predator}

We used 20 male birds to examine whether they reacted differently to the scent of opossums that were recently fed with different diets. In one of the chambers, we placed a paper soiled with the scent of an opossum that consumed chicken bait ( $n=2$ opossums) and in the other a paper soiled with urine of an opossum that ate the fish bait ( $n=2$ opossums). The location of stimuli was balanced between trials.

\section{Data analysis}

We used the software package R 2.12.0 to build generalised linear models with binomial errors and a logit link function (GLM) to analyse whether

1. the treatment (predator chemical cues vs. novel scent) had an effect on the decision of the bird to enter to the experimental chamber (containing the treatment) or the other chamber (control).

2. the most recent meal of the predator - fish or chicken - had an effect on the choice of chamber by the experimental birds.

We did not include the side of the chamber where the treatment was located (left vs. right) as a factor in the analysis because a preliminary analysis indicated that this did not contribute significantly to the models. In all trials, we had to knock on the door of the olfactometry device to stimulate birds to choose one of the chambers; therefore, this variable was not included in the models.

\section{Results}

\section{Detection of chemical cues of a nest predator}

The scent of the experimental chamber determined whether birds avoid it or not $(Z=-2.13, p=0.03$; Figure 2$)$, as most birds avoided the experimental chamber, when it contained opossum scent $(8 / 10)$, but not when it contained a novel scent (3/10).

\section{Detection of the recent diet of an omnivorous predator}

Similar numbers of birds chose the chamber containing the scent of a fish-fed predator $(9 / 20)$ and the side scented by a chicken-fed predator $(11 / 20)(Z=-0.45$, $p=0.66)$.

\section{Discussion}

Our results show for the first time that birds avoid the scent of a marsupial predator, an avoidance behaviour that also been reported in this (Roth et al. 2008) and other bird species (e.g. Amo et al. 2008, 2011a) but in response to the scent of predators of the order Carnivora (e.g. Mustelidae, Amo et al. 2008, 2011a; Felidae, Roth et al. 2008). Therefore, house finches seem to respond to the scent of predators of the Order Carnivora and Marsupial. However, they also avoid the scent of other non-predatory mammals (i.e. the European rabbit; Roth et al. 2008). When foraging, the avoidance of animals other than predators may reduce the possibility of aggressions due to competition for food. Another possibility is that birds in the Roth et al. (2008) experiment were avoiding food that was contaminated with faeces. What 


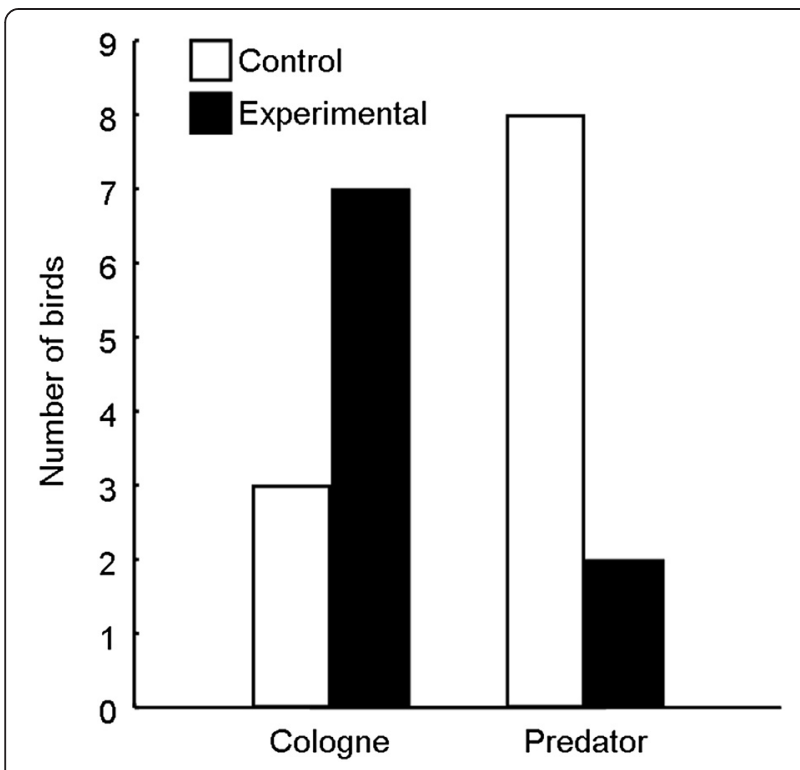

Figure 2 Number of house finches that chose the control side or experimental side of the chamber. Number of house finches that chose the control side of the chamber (odourless, white bars) or the experimental side (black bars) in relation to the treatment (predator vs. novel scent). In the 'predator' treatment, the chamber contained the scent of an omnivorous predator, the common opossum. In the 'novel scent' treatment, the experimental side contained red-fruit scented cologne.

do all the mammals' scent used to test the responses of C. mexicanus have in common to elicit and avoidance response? Different sources of predator scents have been used to elicit avoidance responses in prey (see Apfelbach et al. 2005 for a review in mammals). In birds, for example, Roth et al. (2008) used faeces of cats, Amo et al. (2008, 2011a, b) used urine and gland secretions of ferrets and here we used the urine of common opossums. In all cases, meat digestion may produce sulphurous metabolites in the urine or faeces that may be responsible for the repellent effects of predator odours on potential prey (Apfelbach et al. 2005). However, other non-sulphurous compounds present in the scent of predators, such as the o-aminoacetophenone found in the gland secretions of ferrets (Zhang et al. 2005), are known to be avoided by prey (e.g. Nolte et al. 1993; Zhang et al. 2007) and are even used traditionally as repellents of different species, including birds (e.g. Clark and Shah 1991).

We did not find an effect of the recent diet of the predator on the response of birds, although the ability to react to the recent diet of the predator has been shown in gastropods (Crowl and Covich 1990), insects (Chivers et al. 1996; Wisenden et al. 1997), arachnids (Persons et al. 2001), fishes (Brown and Dreier 2002; Vilhunen and Hirvonen 2003) and amphibians (Wilson and Lefcort 1993; Murray and Jenkins 1999; Kiesecker et al. 2002). In these studies, prey exposed to chemical cues from predators fed with conspecific prey displayed greater antipredatory responses than when confronted to chemical cues from predators fed with heterospecific prey. The mechanism underlying the discrimination of chemical cues of predators fed on different diets is not yet known. In some cases, the alarm cues released by conspecifics when consumed by predators seem to play a role in such discrimination (e.g. Kiesecker et al. 2002), but in other cases, a prey seems able to discriminate the chemical cues of predators alone, without the presence of alarm cues of conspecifics (Murray and Jenkins 1999). In such discrimination, sulphurous odours associated with meat digestion play a role in the repellence of predator urines to potential prey (Nolte et al. 1994). In our case, as both types of bait contain animal proteins, sulphur-containing compounds may not differ sufficiently to allow the birds to discriminate between the different scents offered. Additional chemical analysis of predator scents may clarify whether urine-borne sulphur-containing compounds differed between samples from opossums fed different (vertebrate meat) diets. Further research is also needed to determine whether birds can discriminate between bird-eater, fish-eater and mostly vegetarian predators, and whether sulphurcontaining compounds play a role in such discrimination, as has been previously observed in mammalian prey (Nolte et al. 1994).

Recent predator-diet discrimination may be advantageous to prey species whenever the predators are either stenophagic specialist species or have become specialised through learning (i.e. search image; Punzalan et al. 2005; Fraser et al. 2013; optimal foraging on most common prey, Marples et al. 2005). Since we exposed C. mexicanus to the scent of an omnivore generalist predator, which is likely to prey opportunistically on any prey that becomes available, it may be that the adaptive response to this predator is to ignore its recent diet, even if it was possible for house finches to detect it. This, however, was not guaranteed by our protocol, since the clearance of food through the digestive tract of the opossums may take longer than the few hours they spent in the traps. Further analysis using stable isotopes is needed to assess the time window in which volatile compounds of the prey are excreted by predators. Nevertheless, bird avoidance response of the predator scent is not modified by the recent diet as birds clearly avoided the scent of an opossum fed with chicken in the first experiment, and later in the second experiment, their response of birds to the scent of an opossum fed with fish bait did not differ from that of an opossum fed with chicken. Therefore, house finches exhibited predator avoidance behaviour to both scents. 
The use of chemical cues from predators may be especially important in bird species that during part of their life use habitats in which cues from predators in other modalities, such as visual or auditory, are limited or unavailable. This may happen during the night or in nest cavities (Amo et al. 2008) with scarce visibility. Under these circumstances, chemical cues of nocturnal/crepuscular predators such as the common opossum may provide opportune warning to roosting/nesting birds. For example, great tits $P$. major prefer to sleep outside any nest box when one of the two offered nest boxes contained predator scent (Amo et al. 2011a). This antipredatory strategy may be especially important as the ability to discriminate between the scents of predatory and nonpredatory mammals seems to be impaired during the sleeping period, at least in this species (Amo et al. 2011b).

Our results also suggest that house finches may use chemical cues in a foraging context, as most birds preferred the side of chamber containing a red fruit scent over the water-soiled control. This is an artificial scent, and birds are known to exhibit aversive responses to unknown odours (Jones, Facchin and McCorquodale Jones et al. 2002; reviewed in Roper 1999). However, birds did not avoid the red fruit scent, but rather most of them actually chose it $(7 / 10)$. This suggests a preference for this potentially food-related scent. Although our study was not designed to explore the role of olfaction in foraging, and even though we used an artificial scent, this result suggests that olfaction may help birds to detect ripe fruits. In this species, females preferentially mate with males displaying large, bright patches of red feathers (reviewed in Hill, 2002). Red colour in this (and most animal) species comes from carotenoids obtained from the diet; thus, there is a premium in finding rich sources of carotenoids (Hill, 2002) such as red fruits. Assuming that the odour of the cologne resembles that of red fruit, we suggest that olfaction, together with visual cues, may help birds to discriminate the ripe fruits rich in carotenoids (e.g. Marinova and Ribarova, 2007). This contrasts with the report by Giraudeau et al. (2012), who did not find an effect of the addition of $\beta$-ionone, a compound common in fruits containing carotenoids, on the preferences of seeds by house finches. Their negative results need not imply that house finches do not use chemical cues when foraging on fruits. This is because they 1) may respond to other compounds (or mixtures of compounds) released by carotenoid-rich fruits, different from $\beta$-ionone. Additionally, 2) the scent of sunflower oil used as a control by Giraudeau et al. (2012) may confound their results, since house finches include Compositae seeds in their diet, and many species of Compositae would share chemicals (including sunflower oil). The use of olfaction for foraging has been demonstrated in Procellariiformes (Nevitt et al. 1995) and penguins (Wright et al. 2011; Amo et al. 2013a) that use the dimethyl sulphide for locating the krill concentrations which they feed on (Nevitt 2011). Indeed, to use chemical cues for foraging seems to be an ancestral trait in birds (e.g. Kiwis, Wenzel 1968, 1971; Cathartes vultures, Gomez et al. 1994; Graves 1992; Stager 1964), and it persists in several modern lineages (e.g. zebra finches, Kelly and Marples 2004; chickens Marples and Roper 1996; great tits Amo et al. 2013b). Our results point out the need to conduct further experiments with natural fruits to examine whether olfaction plays a role in fruit ripening detection.

\section{Conclusions}

In sum, our results add to the small but growing pool of evidence indicating that birds can and do use olfaction in predator detection. Further research should evaluate how widespread the use of olfaction is amongst birds, in what other ecological contexts it is used and how it interacts with information in other modalities.

\section{Competing interests}

The authors declare that they have no competing interests.

\section{Authors' contributions}

LA, ILP, IP and CMG designed and performed the experiments. All authors participated in writing the report and approved the final manuscript.

\section{Acknowledgements}

L.A. was supported by a DGAPA-UNAM postdoctoral fellowship, by the Ramon y Cajal programme while writing and I.L.R by a postdoctoral fellowship from the Consejo Superior de Investigaciones Científicas (Spain). We acknowledge support of the publication fee by the CSIC Open Access Publication Support Initiative through its Unit of Information Resources for Research (URICl). The experiments were performed under licence of Secretaría del Medio Ambiente y Recursos Naturales (SEMARNAT).

Received: 4 September 2014 Accepted: 6 February 2015

Published online: 24 February 2015

\section{References}

Amador-Alcala S, Naranjo EJ, Jimenez-Ferrer G (2013) Wildlife predation on livestock and poultry: implications for predator conservation in the rainforest of south-east México. Oryx 47:243-250

Amo L, Galván I, Tomás G, Sanz JJ (2008) Predator odour recognition and avoidance in a songbird. Funct Ecol 22:289-293

Amo L, Visser ME, van Oers K (2011a) Smelling out predators is innate in birds. Ardea 99:177-184

Amo L, Caro SP, Visser ME (2011b) Sleeping birds do not respond to predator odour. PLoS One 6(11):e27576

Amo L, Avilés JM, Parejo D, Peña A, Rodríguez J, Tomás G (2012a) Sex recognition by odour and variation in the uropygial gland secretion in starlings. J Anim Ecol 81:605-613

Amo L, López-Rull I, Pagán I, Macías Garcia C (2012b) Male quality and conspecific scent preferences in the house finch, Carpodacus mexicanus. Anim Behav 84:1483-1489

Amo L, Rodríguez-Gironés MA, Barbosa A (2013a) Olfactory detection of dimethyl sulphide in a krill-eating Antarctic penguin. Mar Ecol: Prog Ser 474:277-285

Amo L, Jansen JJ, van Dam NM, Dicke M, Visser ME (2013b) Birds exploit herbivore-induced plant volatiles to locate herbivorous prey. Ecol Let 16:1348-1355

Apfelbach R, Blanchard CD, Blanchard RJ, Hayes RA, McGregor IS (2005) The effects of predator odors in mammalian prey species: a review of field and laboratory studies. Neurosci Biobehav Rev 29:1123-1144 
Bonadonna F, Nevitt GA (2004) Partner-specific odour recognition in an Antarctic seabird. Science 306:835

Bonadonna F, Caro S, Jouventin P, Nevitt GA (2006) Evidence that blue petrel, Halobaena caerulea, fledglings can detect and orient to dimethyl sulphide. J Exp Biol 209:2165-2169

Brown GE, Dreier VM (2002) Predator inspection behaviour and attack cone avoidance in a characin fish: the effects of predator diet and prey experience. Anim Behav 63:1175-1181

Cantor M, Pires MM, Longo GO, Guimarães PR, Setz EZF (2013) Individual variation in resource use by opossums leading to nested fruit consumption. Oikos 122:1085-1093

Chivers DP, Wisenden BD, Smith RJF (1996) Damselfly larvae learn to recognize predators from chemical cues in the predator's diet. Anim Behav 52:315-320

Clark L, Shah PS (1991) Nonlethal bird repellents: in search of a general model relating repellency and chemical structure. J Wildlife Manag 55:538-545

Crowl TA, Covich AP (1990) Predator-induced life history shifts in a freshwater snail. Science 247:949-951

Eichholz MW, Dassow JA, Stafford JD, Weatherhead PJ (2012) Experimental evidence that nesting ducks use mammalian urine to assess predator abundance. Auk 129:638-644

Eisenberg JF (1989) Order marsupialia. In: Mammals of the neotropics. Vol. I. The northern neotropics. The University of Chicago Press, Chicago and London, pp 27-29

Fraser BA, Hughes KA, Tosh DN, Rodd FH (2013) The role of learning by a predator, Rivulus hartii, in the rare-morph survival advantage in guppies. J Evol Biol 26:2597-2605

Giraudeau M, Toomey MB, McGraw KJ (2012) Can house finches (Carpodacus mexicanus) use non-visual cues to discriminate the carotenoid content of foods? J Ornithol 153:1017-1023

Godard RD, Bowers BB, Wilson CM (2007) Eastern bluebirds Sialia sialis do not avoid nest boxes with chemical cues from two common nest predators. J Avian Biol 38:128-131

Gomez LG, Houston DC, Cotton P, Tye A (1994) The role of greater yellowheaded vultures Cathartes melambrotus as scavengers in neotropical forest. Ibis 136:193-196

Graves GR (1992) Greater yellow-headed vulture (Cathartes melambrotus) locates food by olfaction. J Raptor Res 26:38-39

Helfman GS (1989) Threat-sensitive predator avoidance in damselfish-trumpetfish interactions. Behav Ecol Sociobiol 24:47-58

Hill GE (1990) Female house finches prefer colourful males: sexual selection for a condition-dependent trait. Anim Behav 40:563-572

Hill GE (1991) Plumage coloration is a sexually selected indicator of male quality. Nature 350:337-339

Hill GE (2002) A red bird in a brown bag. The function and evolution of colourful plumage in the house finch. Oxford University Press, Oxford

Hirao A, Aoyama M, Sugita S (2009) The role of uropygial gland on sexual behavior in domestic chicken Gallus gallus domesticus. Behav Proc 80:115-120

Johnson LS, Murphy SM, Parrish GW (2011) Lack of predator-odor detection and avoidance by a songbird, the house wren. J Field Ornithol 82:150-157

Jones RB, Facchin L, McCorquodale C (2002) Social dispersal by domestic chicks in a novel environment: reassuring properties of a familiar odourant. Anim Behav 63:659-666

Kats $L$, Dill $L$ (1998) The scent of death: chemosensory assessment of predation risk by prey animals. Ecoscience 5:361-394

Kelly DJ, Marples NM (2004) The effects of novel odour and colour cues on food acceptance by the zebra finch, Taeniopygia guttata. Anim Behav 68:1049-1054

Kiesecker JM, Chivers DP, Anderson M, Blaustein AR (2002) Effect of predator diet on life history shifts of red-legged frogs, Rana aurora. J Chem Ecol 28:1007-1015

Krause ET, Brummel C, Kohlwey S, Baier MC, Müller C, Bonadonna F, Caspers BA (2014) Differences in olfactory species recognition in the females of two Australian songbird species. Behav Ecol Sociobiol 68:1819-1827

Lima SL, Dill LM (1990) Behavioral decisions made under the risk of predation: a review and prospectus. Can J Zool 68:619-640

Lumpkin HA, Pearson SM, Turner MG (2012) Effects of climate and exurban development on nest predation and predator presence in the southern Appalachian Mountains (U.S.A.). Conserv Biol 26:679-688

Marinova D, Ribarova F (2007) HPLC determination of carotenoids in Bulgarian berries. J Food Comp Anal 20:370-374
Marples NM, Roper TJ (1996) Effects of novel colour and smell on the response of naive chicks towards food and water. Anim Behav 51:1417-1424

Marples NM, Kelly DJ, Thomas RJ (2005) The evolution of warning coloration is not paradoxical. Evolution 59:33-940

Melville HIAS, Conway WC, Morrison ML, Comer CE, Hardin JB (2014) Artificial nests identify possible nest predators of eastern wild turkeys. Southeast Nat 13:80-91

Murray DL, Jenkins CL (1999) Perceived predation risk as a function of predator dietary cues in terrestrial salamanders. Anim Behav 57:33-39

Nevitt GA (2011) The neuroecology of dimethyl sulfide: a global-climate regulator turned marine infochemical. Integ Comp Biol 51:819-825

Nevitt GA, Veit RR, Kareiva P (1995) Dimethyl sulfide as a foraging cue for Antarctic procellariiform seabirds. Nature 376:680-682

Nolte DL, Mason JR, Clark L (1993) Avoidance of bird repellents by mice (Mus musculus). J Chem Ecol 19:427-432

Nolte DL, Mason JR, Epple G, Aronov E, Campbell DL (1994) Why are predator urines aversive to prey? J Chem Ecol 20:1505-1516

Persons MH, Walker SE, Rypstra AL, Marshall SD (2001) Wolf spider predator avoidance tactics and survival in the presence of diet-associated predator cues (Araneae: Lycosidae). Anim Behav 61:43-51

Punzalan D, Rodd FH, Hughes KA (2005) Perceptual processes and the maintenance of polymorphism through frequency-dependent predation. Evol Ecol 19:303-320

Roper TJ (1999) Olfaction in birds. In: Slater PJB, Rosenblat JS, Slater PJB, Rosenblat JS, Snowden CT, Roper TJ (eds) Advances in the study of behavior, 28th edn. Academic Press, Boston, MA, pp 247-332

Roth TC II, Cox JG, Lima SL (2008) Can foraging birds assess predation risk by scent? Anim Behav 76:2021-2027

Smith ME, Belk MC (2001) Risk assessment in western mosquitofish (Gambusia affinis): do multiple cues have additive effects? Behav Ecol Sociobiol 51:101-107

Stager KE (1964) The role of olfaction in food location by the Turkey vulture (Cathartes aura). Los Angeles County Museum Contributions in Science 81:3-63

Staller EL, Palmer WE, Carroll JP, Thornton RP, Sisson DC (2005) Identifying predators at Northern Bobwhite nests. J Wildl Manag 69:124-6132

Thompson WL (1960) Agonistic behaviour in the house finch. Part I: annual cycle and display patterns. Condor 62:245-271

Vilhunen S, Hirvonen H (2003) Innate antipredator responses of Arctic charr (Salvelinus alpinus) depend on predator species and their diet. Behav Ecol Sociobiol 55:1-10

Wenzel BM (1968) Olfactory prowess of the kiwi. Nature 220:1133-1134

Wenzel BM (1971) Olfactory sensation in the kiwi and other birds. Ann NY Acad Sci 188:183-193

Whittaker DJ, Richmond KM, Miller AK, Kiley R, Burns CB, Atwell JW, Ketterson ED (2011) Intraspecific preen oil odor preferences in dark-eyed juncos (Junco hyemalis). Behav Ecol 22:1256-1263

Wilson DJ, Lefcort H (1993) The effect of predator diet on the alarm response of red-legged frog, Rana aurora, tadpoles. Anim Behav 46:1017-1019

Wisenden BD, Chivers DP, Smith RJF (1997) Learned recognition of predation risk by Enallagma damselfly larvae (Odonata, Zygoptera) on the basis of chemical cues. J Chem Ecol 23:137-151

Wright KLB, Pichegru L, Ryan PG (2011) Penguins are attracted to dimethyl sulphide at sea. J Exp Biol 214:2509-2511

Zhang J, Soini H, Bruce K, Wiesler D, Woodley S, Baum M, Novotny M (2005) Putative chemosignals of the ferret (Mustela furo) associated with individual and gender recognition. Chem Senses 30:727-737

Zhang JX, Sun L, Novotny M (2007) Mice respond differently to urine and its major volatile constituents from male and female ferrets. J Chem Ecol 33:603-612

Zhang YH, Du YF, Zhang JX (2013) Uropygial gland volatiles facilitate species recognition between two sympatric sibling bird species. Behav Ecol 24:1271-1278

Zidar J, Løvlie H (2012) Scent of the enemy: behavioural responses to predator faecal odour in the fowl. Anim Behav 84:547-554 